\title{
40. EL GÉNERO ARCTOTHECA VAILL. (ARCTOTIDEAE, COMPOSITAE) EN LA PENÍNSULA IBÉRICA Y BALEARES
}

\author{
María TALAVERA y Salvador TALAVERA
}

Recibido el 27 de octubre de 2015, aceptado para su publicación el 10 de noviembre de 2016

The genus Arctotheca Vaill. (Arctotideae, Compositae) in the Iberian Peninsula and Balearic Islands

Palabras clave. Nomenclatura, distribución, especie invasora, Arctotheca tristis

Key words. nomenclature, distribution, allien species, Arctotheca tristis

Arctotheca es un pequeño género sudafricano deficientemente conocido de la subtribu Arctotidinae (Norlindh, 1977), algunas de cuyas especies han invadido otros territorios de clima mediterráneo, como Australia, $\mathrm{N}$ de América y la propia Región Mediterránea, sobre todo algunas de las formas de Arctotheca calendula, que en los ambientes costeros de la Península Ibérica se comporta como una especie invasora desplazando a las especies autóctonas.

Desde finales del siglo XVIII, el género Arctotheca había sido atribuido a Wendland (1798), quien describió para él solo Arctotheca repens Wendl., una planta decumbente, con raíces adventicias en los tallos, lígulas dentadas y aquenios desprovistos de pelos y vilano. Las plantas con aquenios densamente cubiertos de pelos y con vilano las incluyó Brown (1813:141) en el género Cryptostemma R.Br., con tres especies: C. calendulaceum (L.) R.Br., con lígulas enteras o dentadas; $C$. hypochondriacum (L.) R.Br., con lígulas 3-5-partidas y hojas liradas, y C. runcinatum R.Br., con lígulas 3-5-partidas y hojas runcinadas. Ambos géneros fueron reconocidos por Lessing (1832: 35, 38-40), Candolle (1838: 495-496), Steudel
(1821: 63, 243;1840: 120, 450), Harvey \& Sonder (1865: 466-468) y Beauverd (1915: 51-55). Pero Lewin (1922: 48-50) incluyó el género Cryptostemma R.Br. en Arctotheca Wendl., reconociendo solo cuatro especies: A. repens Wendl., A. forbesiana (DC.) Lewin [Gazania forbesiana DC., Prodr. 6: 508 (1838), basión.], A. calendulacea (L.) Lewin [incluyendo Arctotis calendula L., A. tristis L. y $A$. superba L.] y $A$. nivea (Less.) Lewin [Microstephium niveum Less. in Linnaea 6: 92 (1831), basión].

A pesar de que todos estos autores atribuyeron el género Arctotheca a Wendland (1798), cuyo tipo obligado sería entonces $A$. repens Wendl., Vaillant (1754), en la traducción alemana del trabajo de las Compositae (que inicialmente se publicaron en cuatro partes en sucesivos volúmenes de "Histoire de l'Académie Royale des Sciences, avec les Mémoires de Mathematique et de Physique", entre los años 1718 y 1721), publicó correctamente el género Arctotheca Vaill., cuyo tipo, Arctotis calendula L., fue propuesto por Greuter et al. (2005: 165).

Las especies de Arctotheca, como las de otros géneros de la subtribu Arctotidinae (Arctotis L., ca. 65 especies, del S y SW de

Este trabajo ha sido financiado por el proyecto Flora iberica (CGL2012-32914) y cofinanciado con fondos FEDER 
África; Cymbonotus Gaud., 3 especies, del S de Australia); Dymondia Comton, 1 especie, de Sudáfrica; Haplocarpha Less., ca. 10 especies, de Sudáfrica, Angola, Rodesia, Mozambique, y E. de África), tienen todas las brácteas del involucro libres entre sí, morfológicamente semejantes a las de muchas de las especies de Arctotis, de las que se diferencian, entre otros caracteres, por la sexualidad de las flores liguladas (en Arctotheca estériles, rara vez hermafroditas, y siempre femeninas en Arctotis) y en la anatomía de los aquenios (unilocular en Arctotheca y aparentemente trilocular en Arctotis). Estudios moleculares de secuenciación, con un marcador nuclear y dos del cloroplasto, han mostrado que los cinco géneros de la subtribu, a excepción de Aplocarpha, son monofiléticos, siendo Arctotheca el género hermano de Arctotis (Funk et al., 2007).

Con motivo de la elaboración de las síntesis genéricas de la tribu Arctotideae Cass. para "Flora iberica" se ha encontrado, además de Arctotheca calendula, ya conocida en este territorio, Arctotheca tristis, por lo que exponemos una clave para la identificación de las dos especies que viven en la Península Ibérica y Baleares, además de proporcionar la diversidad morfológica de Arctotheca calendula y la única descripción moderna detallada que existe de Arctotheca tristis, con la esperanza de que con ello se pueda determinar su ecología y variabilidad de esta enigmática especie en la Región Mediterránea.

Arctotheca Vaill. in Königl. Akad. Wiss. Paris Phys. Abh. 5: 604 (1754)

$\equiv$ Cryptostemma R.Br. in Aiton, Hort. Kew., ed. 2, 5: 141 (1813) [Tipo: Arctotis calendula L.]

=Arctotheca Wendl., Bot. Beob.: 41 (1798)

[Tipo: Arctotheca repens Wendl.]

= Alloiozonium Kunze in Linnaea 16: 472

(1843) [Tipo: Alloiozonium arctotideum Kunze]
Hierbas anuales o perennes, caulescentes, erectas o ascendentes, a veces enraizantes en los nudos inferiores, uni- o pluricaules, inermes, con indumento araneoso formado por pelos largos pluricelulares, blanquecinos y adpresos, la mayoría de ellos tricelulares con la célula basal cilíndrica, la intermedia globosa y la apical delgada y muy larga, en los tallos, hojas, dorso de las brácteas del involucro y en las páleas del receptáculo, cuando existen, a veces acompañados de pelos moniliformes y hialinos, rojizos en los pedúnculos, además de pelos glandulíferos pediculados o sésiles en el dorso de la corola, papilas \pm desarrolladas en los filamentos estaminales cercanos a las anteras y pelos unicelulares uni- y pluriseriados originando un indumento algodonoso que oculta completamente los aquenios y vilanos; sistema radical axonomorfo largo y delgado, o corto, grueso, con raíces fasciculadas, a veces leñoso y ramificado en el ápice, originando cada rama brotes reproductores. Tallos cilíndricos, estriados longitudinalmente, ápteros, foliosos, simples o más frecuentemente ramificados desde la base, con las ramas frecuentemente monocéfalas. Hojas alternas, pecioladas, lanceoladas u oblanceoladas, rara vez espatuladas, enteras, dentadas o más frecuentemente pinnadas o bipinnadas, runcinadas o liradas, con 2-8 pares de lóbulos laterales sésiles, triangulares o elípticos, dentados, lobados o pinnatisectos, el terminal con frecuencia \pm cordiforme y mucho mayor que los laterales, a veces triangular y menor que los laterales; las basales con el pecíolo más largo o de la longitud del limbo, marcescentes o caedizas en la floración; las caulinares con el pecíolo generalmente corto y ancho, que abraza al tallo. Capítulos largamente pedunculados, rara vez subsésiles, erectos o péndulos antes de la antesis, erectos en la floración y erectos, semipéndulos o péndulos en la fructificación, solitarios, multifloros, radiados, homógamos o heterógamos; pedúnculos cilíndricos, estriados, generalmente sin brácteas. Involucro 
campanulado u ovoide en la floración, \pm cónico u ovoide en la fructificación, y en forma de estrella u ovoide en la dispersión, truncado o atenuado en la base, con 4-6(7) series de brácteas \pm adpresas, imbricadas, libres entre sí, las externas más cortas que las internas; brácteas ovado-lanceoladas o elípticas, verdosas, generalmente con 4 nervios paralelos bien marcados, las externas y medias con un apéndice apical linear o lanceolado, generalmente cubierto de numerosos pelos hialinos moniliformes, las más internas elípticas, sin apéndice, obtusas, con margen escarioso \pm ancho y frecuentemente teñido de púrpura en la mitad superior. Receptáculo plano en la dispersión, alveolado, con los alvéolos pentagonales, rodeados por una corona escariosa entera o denticulada, o cónico y con páleas florales herbáceas, semejantes a las brácteas del involucro, glabro. Flores más externas del capítulo liguladas, (2)3(4)-dentadas y estériles, 3-5-fidas, unilaterales o incluso bilabiadas, la mayoría estériles y algunas hermafroditas, sobre todo las bilabiadas; las centrales flósculos, con 5 dientes, hermafroditas, o las de los ciclos más externos del capítulo hermafroditas y las los ciclos centrales funcionalmente masculinas. Corola brillante, laxa o densamente recubierta de pelos glandulíferos pediculados o subsésiles, con la glándula esférica o elíptica, amarillenta, brillante, con el pie pluricelular, \pm translúcido; las de las flores liguladas o bilabiadas de un amarillo dorado, verde-purpúreas por el dorso, (2)3(4)-dentadas o 3-5-fidas, generalmente con 4 nervios paralelos; las de los flósculos de un amarillo pálido, con los dientes \pm purpúreos. Estambres con filamentos \pm papilosos; anteras obtusas en el ápice, sagitadas en la base, con los sacos polínicos que ocupan la parte central de la antera, negro-purpúreas, rara vez amarillentas. Estilo cilíndrico, brillante, diferenciado en dos partes; la inferior más delgada, glabra y amarillenta, de mayor longitud que la superior; la superior truncada en la base, papilosa, con las papilas colectoras de polen más desarrolladas en la base, formando un anillo, generalmente purpúrea; ramas estilares elípticas, divergentes, frecuentemente amarillentas, con el estigma cubriendo toda la superficie ventral de las ramas. Aquenios homomorfos, urceolados, coriáceos, comprimidos en el ápice, formando una corona lobulada y blanco-nacarada que rodea al vilano, atenuados en la base formando un pedículo o carpopodio, \pm aplanados por el vientre, \pm convexos por el dorso, \pm rugulados transversalmente, pardo-obscuros, sin costillas o con 1-5 costillas longitudinales, 1-3 dorsales y 2 laterales, densamente cubiertos de un indumento algodonoso que recubre la totalidad del pericarpo y carpopodio, a veces glabros en la cara ventral, con vilano, rara vez sin vilano en los aquenios más externos del capítulo. Vilano escamoso, con 2-8 escamas dispuestas en 1 fila, cubierto por el indumento del aquenio; escamas libres entre sí, planas, erosas en el margen, agudas u obtusas, glabras, blanquecinas o rosadas, persistentes. $x=9$.

\section{Clave para las especies}

1. Flores liguladas (2)3(4)-dentadas, estériles; receptáculo plano en la fructificación, sin páleas entre las flores; flósculos hermafroditas, todas aptos para la formación de frutos; pedúnculos sin brácteas, densamente cubiertos de pelos moniliformes y purpúreos en la mitad superior ................................... 1. A. calendula

-. Flores liguladas o bilabiadas 3-5-fidas, estériles o hermafroditas; receptáculo cónico en la fructificación, con una pálea junto al dorso de cada flor, semejante a las del involucro, al menos en los ciclos más externos; flósculos de los ciclos más externos del capítulo hermafroditas, aptos para la formación de frutos, los centrales funcionalmente masculinos, con el ovario poco desarrollado y sin vilano; pedúnculos por lo general con hojas bracteiformes, a veces, casi hasta el ápice, sin pelos moniliformes .

2. A. tristis

1. Arctotheca calendula (L.) Levyns in J. S. African Bot. 8: 284 (1942)

$\equiv$ Arctotis calendula L., Sp. Pl.: 922 (1753)

[basión.]

ECryptostemma calendula (L.) Druce, Rep. 
Bot. Exch. Cl. Brit. Isles 1913, 3: 416 (1914)

$\equiv$ Arctotis calendulacea L., Syst. Nat., ed. 12, 2: 578 (1767), nom. illeg. [non Hill. 1761]

EArctotis speciosa Salisb., Prodr. Stirp. Chap. Allerton: 209 (1796), nom. illeg.

三Cryptostemma calendulaceum (L.) R. Br. in Aiton, Hort. Kew., ed. 2, 5: 141 (1813), nom. illeg.

$\equiv$ Arctotheca calendulacea (L.) K. Lewin in Reppert. Spec. Nov. Regni Veg. Beih 11: 49 (1922), nom. illeg.

Ind. loc.: "Habitat in Aethiopia." [Lectótipo designado por Wijnands, Bot. Commelins: 66 (1983): LINN No. 1036.7]

Hierba anual o perenne de 10-40(50) $\mathrm{cm}$ de altura, caulescente; sistema radical axonomorfo, largo y delgado, o más frecuentemente corto y grueso, con raíces fasciculadas, a veces algo lignificado y ramificado en el ápice, originando cada rama rosetas de hojas y tallos. Tallos de 1-10 $\mathrm{mm}$ de diámetro en la base, estriados longitudinalmente, blanco-tomentosos, con la mayoría de los pelos tricelulares, con la célula basal cilíndrica, corta, la intermedia \pm esférica y la apical muy larga, sigmoidea y delgada, generalmente ramificados en la base, erectos o ascendentes, frecuentemente enraizantes en los nudos. Hojas (1)4-25(45) x (0,5)1,5-6(8) cm, pecioladas, con el pecíolo semiamplexicaule, desde más corto hasta más largo que la longitud del limbo, oblanceoladas, rara vez espatuladas, enteras, dentadas, pinnatífidas o pinnatisectas, con 2-8 pares de lóbulos laterales -a veces no enfrentados entre sí-, dentados, lobados, pinnatífidos o pinnatisectos, agudos u obtusos, el terminal frecuentemente mucho mayor que los laterales, hasta de $7 \times 8 \mathrm{~cm}$, con haz verdoso o cano-tomentoso, con todos los pelos gruesos, pluricelulares, papiliformes, hialinos, hasta de $0,8 \mathrm{~mm}$, generalmente acompañados de pelos tricelulares, largos y blancos como los del tallo, y envés blanco-tomentoso, con los mismos tipos de pelos que en su haz, sobre todo en los nervios; las basales algo más cortas que las caulinares, generalmente marchitas en la floración; las caulinares alternas, generalmente concentradas en la mitad inferior del tallo. Capítulos solitarios al final de las ramas, largamente pedunculados, péndulos en preantesis y en la fructificación, erectos en la floración, multifloros, radiados, homógamos; pedúnculos $(2,5) 3-10(12,5) \mathrm{cm}, \pm$ cilíndricos, blanco-tomentosos, por lo general densamente cubiertos cerca del ápice de pelos moniliformes $\mathrm{y} \pm$ purpúreos hasta de $2 \mathrm{~mm}$, patentes, con la célula apical terminada en una especie de cilio muy fino. Involucro (6)7-14(16) x (6)7-15(16) $\mathrm{mm}$, truncado en la base, campanulado en la floración, \pm ovoide en la fructificación y en forma de estrella en la dispersión, con 4-6(7) series de brácteas libres entre sí, adpresas, crecientes en tamaño hacia el interior del capítulo; brácteas ciliadas, \pm aracnoideas por el dorso, por lo general con 4 bandas verdosas longitudinales, las externas y medias agudas, de 2-7 x 1-3 mm, con un apéndice apical \pm recurvo de $0,8-3,5 \times 0,21 \mathrm{~mm}$, linear o lanceolado, densamente cubierto, sobre todo por el margen, de pelos moniliformes hialinos de 1,5-2 $\mathrm{mm}$, las internas 6,5-12 x 2,5-5 mm, elípticas, obtusas, con margen escarioso generalmente purpúreo en la mitad superior. Receptáculo alveolado, plano, glabro, con los alvéolos pentagonales rodeados por una corona escariosa, dentada y blanca, sin páleas entre las flores. Flores de la periferia del capítulo, en número de 7-24, liguladas, estériles, solo con el ovario desarrollado pero carentes de óvulo, las del centro del capítulo flósculos, numerosos, hermafroditas. Corola brillante, recubierta de pelos glandulíferos pediculados o sésiles; las de las flores liguladas de 8-25(30) mm, (2)3(4)-dentadas o enteras, con tubo de 1,5-2 mm, glabro, de un amarillo pálido y el limbo de 6-23(29) x 1,5-4(5) mm, linear-elíptico, unilateral, con los dientes de 0,2-0,5 x 0,1-0,2 mm, con 4 nervios paralelos que se unen un poco por debajo de los dientes, 
laxamente cubiertos por el dorso de pelos glandulíferos pluricelulares y pediculados con la glándula esférica o elíptica, muy brillante, de un amarillo dorado o pálido por el vientre, con los nervios purpúreos, y de un verde-azulado o verde-púrpúreo por el dorso; las de los flósculos de (2,9)3-4(5) mm, laxa- o densamente cubierta por el dorso de pelos pluricelulares glandulíferos, semejantes a los de las lígulas, con tubo de 0,3-0,5(1) $\mathrm{mm}$, amarillento y limbo de 2,5-3,5 mm, amarillento, con los 5 dientes de 1-1,2 x 0,3-0,5 mm, a veces recurvados, purpúreos en la mitad superior. Anteras (1,3)1,5-2,5 mm, purpúreas. Ramas estilares 0,3-0,7 x 0,2-0,4 mm, elípticas, amarillentas. Aquenios 2,1-2,8 x 1,2-1,7 mm, urceolados, convexos por el dorso, con 1-5 costillas longitudinales, 1-3 dorsales y 2 laterales, o sin costillas diferenciadas, con el pericarpo enteramente recubierto por un indumento algodonoso formado por pelos bicelulares en el carpopodio y pluricelulares, uniseriados y pluriseriados, mezclados con bicelulares, en el exocarpo, con vilano, muy rara vez sin vilano en los aquenios externos del capítulo. Vilano 0,9-1,5 x 0,3-1 mm, escamoso, formado por (2)4-8 escamas desiguales, elípticas o lanceoladas, agudas u obtusas, escariosas, erosas, libres entre sí, insertas en el interior de la corona del aquenio, glabras, blanquecinas, amarillentas o rosadas, persistentes. $2 \mathrm{n}=18$.

Ecología y fenología. Ruderal, viaria, arvense, a veces en sotobosques de alcornocales y pinares, también con mucha en dunas y arenas litorales, desde el nivel del mar hasta $200 \mathrm{~m}$. Florece y fructifica de febrero a julio (agosto).

Distribución. Nativa de Sudáfrica; naturalizada en el S de Europa, SW de África, W de Estados Unidos de América, y S de Australia. En la Península Ibérica se encuentra en casi todas las provincias litorales, pero es mucho más frecuente en el SW de España, donde llega a comportarse como invasora, desplazando a las especies autóctonas. Se tiene constancia de su presencia en Portugal desde principios del siglo XIX, donde ya fue citada por Brotero (1804: 401) como Arctotis acaulis, non L., y por Hoffmannsegg \& Link (1820-1834: 401), como Arctotis hypochondriaca, non (L.) Willd.

\section{Material estudiado (selección).}

ESPAÑA. ALICANTE. Teulada, L'Andrago (VAL-83268); Guardamar de Segura (ABH-11693). ALMERÍA. Pulpi, El Cocedero (MA-612176). BADAJOZ. Badajoz, proximidades del recinto ferial (UNEX-6459); ídem (UNEX-10876); Badajoz, margen del río Guadiana (UNEX-34165). LUGO. Cervo, San Ciprian (MA-345368). BILBAO. Laga, playa de Laga (SALA-96555); ídem (VAL-108689). LA CORUÑNA. Camariñas, cerca del faro del Cabo Vilano (ABH-43031); Doniños, playa de Doniños (SEV-60457); Miño (SANT-20881); Boa, Noia (SANT-19985); Dumbría, Ezaro, paseo marítimo (SANT-36076); Carnota, playa (SANT-36077); Testal, playa de Testal (SANT-15472). CÁDIZ. Tarifa, Punta Paloma (ABH-30867); Cádiz, arenales marítimos (SEV-212214); Rota, pinares (SEV-60457); entre Cádiz y San Fernando (SEV-15339); Barbate, puerto de Barbate (SEV-57169); entre Puerto Real y Chiclana de la Frontera (SEV-44651). CÁCERES. Hervás (SALA-99728). CASTELLÓN. Nules, playa (VAL-18656); ídem (VAL-189631); Almassora (VAL-221306). GERONA. Sant Marti d'Empules (MA-867955). GRANADA. Almuñecar, playa de la Herradura (MGC-3754). HUELVA. Almonte, junto al puente de la Rocina (MGC-50291); Isla Cristina (SEV-286419); Hinojos, pinares (SEV-286417); Moguer, Los Cabezudos (SEV-286405); Punta del Moral (SEV-242815); El Rompido (SEV-274022). MÁLAGA. Torre del Mar, playa (MGC-7663); ídem, campo de golf(MGC-69472); Manilva, Punta Chullera (MGC-67195); brazo del encauzamiento del río Guadalhorce (MGC-54110); Marbella, arenales cerca de la playa (SEV-59814). MURCIA. Águila, La Carolina (MA-613461 y MUB-101650). OVIEDO. Gozón, playa de Bañugues (ABH-46293, ABH-41378, SANT-41486 y MA-77371); Villaviciosa (SALA-85562). MALLORCA. Antiguo campo de deporte del Real Club Mallorca 
(MA-131029). PONTEVEDRA. Cangas de Morrazo (SALA-6698); Louriza (SALA-646); O rosal (SANT-27631 y 27632); Cangas, pinar de la playa (SANT-57422); Morrazo, San Pedro de Cangas (SANT-52700). SAN SEBASTIÁN. Zarautz (MA-704643). SANTANDER. San Vicente de la Barquera (MA-684849); Santoña, (MA-833907). SEVILLA. Villamanrique de la Condesa (MGC-48548); La puebla, Venta del Cruce (SEV-51147); Sevilla, campo de feria (SEV-212216); ídem, El Plantinal (SEV-269553). TARRAGONA. Cambrils (MA-615034). VALENCIA. El Saler, La Dehesa,(VAL-86391); Carelt de En Berengues (VAL-155730); El Saler, Dehesa de la Albufera (VAL-188765).

PORTUGAL. ALGARVE. Olhao (ABH-30867); Cabo de San Vicente, pr. Sagres (SEV-61441 y MA-238554); Manta Rota (SEV-35717); Carrapateira (MA-239179); playa de Cuarteira (MGC-13759 y MGC-13737); Fuseta (MA-835140). ALTO ALENTEJO. Elvas, junto a la vía Elvas-Arronches (SEV-83684 y MA-351735).

BAIXO ALENTEJO. Lagoa de Santo André (MA-239182 y SEV-37659); Cabo Espichel (ABH-50538); Lagoa de Melides (MA-448099); Cabo de Sines (MA-239180 y SEV-37659). BEIRA LITORAL. Aveiro (MA-656074); Figueira da Foz (MA-867101); Esmoriz (MA-239186). DOURO LITORAL. Leixoes (MA-339176); Oporto (MA-351671). ESTREMADURA. Peniche (VAL-211178); Cascais, S. Pedro de Estoril, pr. ribeira de Caparide (SEV-121201); Cabo de Roca (ABH-67742); entre Cabo Espichel y Lisboa (ABH-50538). MINHO. Esposende (VAL-204651 y ABH-56964). RIBATEJO. Entre Apiarca y Chamusca (SEV-212218).

Observaciones. Especie muy variable en el territorio de esta flora. Las poblaciones que florecen en invierno, entre enero y marzo, suelen integrarlas plantas de (10)15-25(35) cm de altura, por lo general anuales, con sistema radical axonomorfo, delgado y cubierto de raíces finas. Presentan tallos de 0,2-0,3(0,35) $\mathrm{mm}$ de diámetro en la base, erectos, simples o poco ramificados, con las hojas basales y alternas ya marchitas, las caulinares de (1)2-10(14) x 1-2(3,5) cm, espatuladas u oblanceoladas, muy frecuentemente indivisas o pinnatífidas con (1)2(3) pares de lóbulos laterales y elípticos, por lo general liradas, con el lóbulo terminal de 2-3(4) x 1-2(3,5) cm, \pm cordiforme, dentado, mucho mayor que los laterales; capítulos con pedúnculo de 3-10(30) $\mathrm{cm}$, hasta de $0,3 \mathrm{~mm}$ de diámetro en la base; involucro (7)8-9 x 6,5-7 $\mathrm{mm}$ en la antesis, con 4-5 series de brácteas adpresas, las 2-3 más externas con un apéndice apical linear de 0,2-0,8(1) mm, \pm erecto-patente, densamente cubierto de pelos moniliformes e hialinos de 0,3-1 mm; flores liguladas, en número de (7)9-14(15) por capítulo, de 8-14 mm; aquenios sin costillas o más frecuentemente con 1 costilla dorsal solamente, o con 3 costillas, 1 dorsal y 2 laterales; vilano $0,8-0,9 \mathrm{~mm}$, formado por 5-7 escamas frecuentemente rosadas. Con esta variabilidad hay plantas con tallo simple y hojas indivisas, que se identifican con Crystostemma calendulaceum var. integrifolium Less., Syn. Compos.: 40 (1832), mientras que las de tallo a menudo poco ramificado y hojas divididas se identifican con el tipo de Arctotheca calendula L. Estas plantas se distribuyen por el litoral del Atlántico, sobre todo en pinares o alcornocales y a veces también en los sistemas dunares.

Las poblaciones que florecen en primavera, entre marzo y mayo, prefieren ambientes mucho más antrópicos, y se comportan casi como ruderales, Suelen constituirlas plantas perennes o perennizantes, robustas, hasta de $50 \mathrm{~cm}$ de altura, con sistema radical corto, grueso y ramificado en el ápice, con raíces fasciculadas. Presentan tallos mayores de $5 \mathrm{~mm}$ de diámetro en la base, muy ramificados, por lo general ascendentes, a veces enraizantes en los nudos, con las ramas también ramificadas; hojas hasta de 25-45 x 5-8 cm, la mayoría formando rosetas en la base de los tallos, oblanceoladas, frecuentemente runcinadas, pinnatífidas, pinnatisectas o bipinnatisectas, con 4-8 pares de lóbulos triangulares o elípticos $\mathrm{y} \pm$ dentados, el terminal de 3-7 x 5-8 cm, anchamente elíptico, dentado-lobado, mucho mayor que los 
laterales; capítulos con pedúnculo de 4,5-12,5 $\mathrm{cm}$, hasta de $0,5 \mathrm{~mm}$ de diámetro en la base. Involucro 11-17 x 13-16 mm, con 5-6 series de brácteas adpresas, las 3-4 externas con el apéndice apical lanceolado de 3-4 x 1-1,1 $\mathrm{mm}, \pm$ recurvo, densamente cubierto de pelos moniliformes e hialinos de 1-2 mm; flores liguladas, en número de 20-24 por capítulo, de 17-30 mm; aquenios generalmente con 5 costillas, 3 dorsales y 2 laterales; vilano 1-1,5 $\mathrm{mm}$, formado por 2-8 escamas \pm parduscas, rara vez sin vilano. Por los tallos a veces enraizantes en los nudos, el tamaño y número de lígulas en el capítulo y por el número de costillas de los frutos, algunos de ellos sin vilano, estas plantas se podrían identificar con Arctotheca prostrata (Salisb.) Britten in J. Bot. 54: 61 (1916) [Arctotis prostrata Salisb., Prodr. Stirp. Chap. Allerton: 210 (1796), basión; Arctotheca repens J.C. Wendl., Bot. Geob.; 41 (1798)]. Entre el material estudiado son frecuentes también plantas cuyos aquenios portan vilano con solo 2 escamas, y parecidos a los descritos en Arctotheca cryptostemoides Beauverd in Bull. Soc. Bot. Genève, $2^{\mathrm{a}}$ ser., 9: 52 (1915), pero con 3 costillas, y no 5 como en Arctotheca prostrata. Las plantas con hojas pinnatífidas se identifican con Cryptostemma calendulaceum var. pinnafidum Less., Syn. Compos.: 40 (1832), y las de hojas bipinnatífidas con Cryptostemma calendulaceum var. bipinnatifidum Less., Syn. Compos.: 40 (1832). Estas dos variedades conviven en la mayoría de las poblaciones en el suroeste de España, y no son reconocidas aquí con categoría taxonómica.

Plantas con caracteres intermedios entre las dos grandes tendencias de variación más arriba señaladas, pero generalmente con 4 costillas longitudinales en los aquenios -2 dorsales y 2 laterales-, son las más frecuentes entre los meses de mayo y julio, y son parecidas a las descritas como Arctotheca grandiflora Schrad., Ind. Sem. Hort. Goett.: 1 [adnot] (1832), aunque en las mismas poblaciones existen plantas cuyos aquenios presentan 1-5 costillas, e incluso sin costillas.

Todas estas variaciones se pueden encontrar, sucesivamente, desde mediados de invierno hasta bien entrado el verano, lo que sugiere que, bajo Arctotheca calendula, podrían existir realmente dos especies, Arctotheca calendula s.s. y $A$. prostrata, y sus híbridos, descritos como Arctotheca x grandiflora. Estudios de ecología, biología de la reproducción $y$, sobre todo, moleculares, serían necesarios para esclarecer el verdadero valor de estas variaciones.

2. Arctotheca tristis (L.) M. Talavera \& Talavera, comb. nov.

$\equiv$ Arctotis tristis L., Sp. P1.: 922 (1753) [basión.]

$\equiv$ Arctotis calendulacea var. tristis (L.) L., Syst. Nat., ed.12, 2: 178 (1767)

$\equiv$ Cryptostemma triste (L.) Domin in Mem. Soc. Sci. Boheme 1921-1922, 2: 124 (1923) = Arctotis superba L., Cent. P1. II: 32 (1756) [Ind. loc.: "Habitat in Aethiopia.". Lectótipo, designado aquí: Herb. Linn. $\mathrm{N}^{\mathrm{o}}$ 1036.1(LINN), excluído el capítulo con pedúnculo; ver observaciones)]

$\equiv$ Arctotis calendulacea var. superba (L.) L., Syst. Nat., ed. 12, 2: 178 (1767).

= Arctotheca calendulacea var. coruscans L., Syst. Nat., ed. 12, 2: 178 (1767) [Ind. loc.: no expresada. Tipo: no encontrado]

= Arctotis calendulacea var. hypochondriaca L., Syst. Nat., ed. 12, 2: 178 (1767) [Ind. loc.: no expresada. Tipo: no localizado] $\equiv$ Arctotis hypochondriaca (L.) Willd., Sp. P1. 3(3): 2348 (1804)

$\equiv$ Cryptostemma hypochondriacum (L.) R. Br. in Aiton, Hort. Kew., ed. 2, 5: 141 (1813) $\equiv$ Cynotis hypochondriaca (L.) Hoffmanns., Verz. Pfl.-Kult. Nachtr. 2: 98 (1826)

= Cryptostemma runcinatum $\mathrm{R}$.Br. in Aiton, Hort. Kew., ed. 2, 5: 141 (1813) [Ind loc.: "Nat. of the Cape of Good Hope. Mr. Fr. Masson. Introd. 1794. Fl. July and August". Tipo: no localizado] 
$\equiv$ Arctotis runcinata (R.Br.) Hoffmanns., Verz. Pfl.-Kult.: 40 (1824)

ECryptostemma calendulaceum var. runcinatum (R. Br.) Harv. \& Sonder, Fl. Capensis 3: 467 (1864-1865)

Ind. loc.: "Habitat in Aethiopia".

Lectótipo designado aquí (iconótipo): J. G. Volckamer (1700: 224-225), Flora Noribergensis, lám. s.n. in Addenda \& subjungenda: "Iacoboea Africana Stoebes facie, flore amplo, petalis radiantib. trifidis"

Hierba perenne, caulescente, decumbente o ascendente, con sistema radical corto, grueso, hasta de $10 \mathrm{~mm}$ de diámetro, ramificado $\mathrm{y}$ algo leñoso en el ápice, originando cada rama una roseta de hojas y tallos. Tallos de de $8-17 \mathrm{~cm}$ de altura y 1-2(3) $\mathrm{mm}$ de diámetro en la base, estriados longitudinalmente, enraizantes en los nudos inferiores, ascendentes o casi decumbentes, blanco-tomentosos, con la mayoría de los pelos tricelulares, con la célula basal cilíndrica, corta, la intermedia \pm esférica y la apical muy larga, sigmoidea y delgada, ramificados en la base. Hojas basales 3,7-11 x 1-3 $\mathrm{cm}$, pecioladas, con pecíolo semiamplexicaule, desde más corto que el limbo o hasta casi de su longitud, oblanceoladas, bipinnatisectas, con 3-6 pares de lóbulos laterales, generalmente no enfrentados, bipartidos, con la parte apical mayor que la basal, de margen generalmente dentado, agudos, el terminal a veces más pequeño que los laterales, hasta de $2 \times 2 \mathrm{~cm}$, cuneiforme, crenado, con haz cano-tomentoso y envés blanco-tomentoso, con todos los pelos tricelulares, semejantes a los del tallo, sin pelos pluricelulares hialinos; las caulinares alternas, concentradas en la mitad inferior del tallo, a veces dispuestas hasta la base del capítulo, pero enteras y mucho más pequeñas que las basales. Capítulos solitarios al final de las ramas, subsésiles o pedunculados, erectos en preantesis, en la floración y en la fructificación, multifloros, radiados, heterógamos; pedúnculos (0,5) 2-6 cm, cilíndricos, blanco-tomentosos, con todos los pelos tricelulares, como los del tallo y hojas, sin pelos moniliformes. Involucro 7-8 x 7-8 mm, truncado o atenuado en la base, campanulado u ovoide en la floración, \pm ovoide en la fructificación y dispersión, con 4-5 series de brácteas libres entre sí, adpresas, crecientes en tamaño hacia el interior de capítulo o todas casi de la misma longitud; brácteas ciliadas, aracnoideas por el dorso, con 3-4 bandas verdosas longitudinales, o sin bandas, las externas y medias de 2-4 x 0,7-1,4 mm, ovallanceoladas, agudas, con un apéndice apical \pm recto menor de $1 \mathrm{~mm}$, linear, cubierto de pelos moniliformes hialinos menores de $1 \mathrm{~mm}$, o sin apéndice, las más internas de 4-7 x 1,2-2,2 $\mathrm{mm}$, elípticas, obtusas, frecuentemente con margen escarioso \pm blanquecino en el ápice. Receptáculo cónico, con páleas entre las flores, o a veces faltan en los ciclos de flores más internos; páleas semejantes en tamaño, consistencia e indumento, a las brácteas más internas del involucro, por lo general cuculadas, incurvas, cubriendo una sola flor flosculosa cada una. Flores más externas del capítulo en número de 12-14, liguladas o bilabiadas, estériles o hermafroditas, las estériles solo con ovario pero sin rudimento seminal, las hermafroditas con androceo y gineceo bien desarrollados; las centrales del capítulo flósculos, los de los ciclos más externos del capítulo hermafroditas, y los internos funcionalmente masculinos. Corola brillante, \pm recubierta de pelos glandulíferos pediculados o subsésiles, pluricelulares, con la glándula esférica o elíptica; la de las flores liguladas y bilabiadas de 6-14 mm, 3-5-fida, con el tubo de 1-2 mm, y el limbo de 5-12 mm, de un amarillo limón, con el dorso \pm verdoso -las corolas trífidas y unilaterales con los lóbulos lineares de 3,5-8 x 0,3-0,4 mm; las bilabiadas 3-4-fidas, bipartidas, con el lóbulo superior o dorsal entero o bífido y el inferior o ventral bífido, con divisiones de $6-8$ x 0,3 mm; las bilabiadas 5-fidas, la mayoría hermafroditas, bipartidas, con el labio superior bífido o trífido, con divisiones de 1,5-8 x 0,3-0,5 mm, y el 
inferior bífido o trífido con las divisiones de 1-3 x 0,1-0,5 mm-; flósculos de 3-4 mm, 5-dentados, con tubo de 0,3-0,5 mm, amarillento, y limbo de 2,7-3,5 mm, en los flósculos más externos del capítulo dientes de 1,3-1,5 x 0,4-0,7 mm, y en los internos de c. 1 x $0,5 \mathrm{~mm}$, de un amarillo claro o amarillo-verdoso, con el ápice de los dientes purpúreo. Anteras purpúreas, rara vez amarillas; las de las flores bilabiadas de 1,4-1,5 $\mathrm{mm}$; las de las flósculos más externos del capítulo de 1,5-2 mm; las de los flósculos más internos del capítulo de 2-3 $\mathrm{mm}$, con mayor cantidad de polen que en las de los flósculos más externos. Ramas estilares amarillentas; las de las flores bilabiadas de 0,7-0,8 x 0,3-0,4 $\mathrm{mm}$, ovadas, patentes; las de los flósculos externos del capítulo de 0,6-0,7 x 0,3 mm, subespatuladas, patentes; las de los flósculos más internos de c. $0,5 \times 0,5 \mathrm{~mm}$, anchamente elípticas, erecto-patentes. Aquenios 2-3 x 1,2-1,4 mm, urceolados, débilmente convexos por el dorso, o biconvexos, sin costillas o con 3 costillas longitudinales -2 laterales y 1 dorsal-, enteramente cubiertos de pelos unicelulares largos, excepto el vientre que a veces es glabro. Vilano 0,8-3 mm, escamoso, formado por 4-8 escamas lanceoladas y erosas en el margen, desiguales, libres entre sí, insertas en el interior de la corona del aquenio, blanquecinas, persistentes.

Ecología y fenología. Ruderal, viaria o arvense, en substratos arenosos o francoarenosos, irrigados o húmedos; 100-110 m. Florece de julio a octubre.

Distribución. Oriunda de Sudáfrica, se ha naturalizado en el SW de España (Huelva), donde se reproduce con normalidad.

Material estudiado. ESPAÑA. HUELVA: Hinojos, Pino Gordo, huertos irrigados, substrato arenoso - franco arenoso (SEV-285918, SEV-285919 y SEV-286380); ídem, junto a los canteros de un huerto (SEV-285895).

\section{Observaciones.}

La mayoría de los autores han considerado a Arctotheca tristis o sus distintos sinónimos como variedad de Arctotheca calendula, pero no existe ninguna descripción moderna detallada de esta planta linneana ni tampoco de sus sinónimos, más allá de las observaciones sobre las flores externas del capítulo 3-5-fidas o partidas, de las hojas bipinnatisectas o bipinnatífidas, y de la observación que hizo Candolle (1838: 496) en plantas cultivadas de Cryptostemma hypochondriaca sobre la presencia de páleas entre los flósculos. Las diferencias morfológicas y fenológicas encontradas en las plantas de Andalucía son tan notables que se duda en considerar Arctotheca tristis como una especie autónoma, muy diferente de los distintos morfotipos de Arctotheca calendulacea.

\section{Titificación de Arctotis tristis L.}

Respecto de la tipificación de Arctotis tristis L., cabe señalar que Linneo (1753) señaló en su descripción "tristis. 1. Arctotis flosculis radiantibus vicenis trifidis. Artotis foliis pinnatifidis, caule herbáceo, petalis radii profunde trifidis. Ray. Lugdb. 179. Anemospermos afra, foliis \& facie taraxaci incanis. Breyn. ic. 27.t.15. Habitat in Aethiopia". En su herbario principal se conserva un pliego (LINN: $\mathrm{N}^{\circ} 1036.8$ ) con material cultivado en el jardín de Upsala, según figura en la base del mismo (H.U.), que contiene un capítulo en floración, con su pedúnculo, y en la base de éste dos hojas, una a cada lado. Este material, que fue identificado por Linneo como Arctotis calendulacea, es heterogéneo, el capítulo tiene las flores radiadas, parcialmente carcomidas, tripartidas o trífidas, como indicó Linneo en la descripción de su $A$. tristis, pero las hojas se identifican como de Arctotis calendula L. Arctotis calendulacea L. (1767) es un nombre ilegítimo, por supérfluo, ya que bajo este nombre incluyó, no solo a $A$. calendula con 
las lígulas casi enteras, sino también a todas las variedades que hizo de plantas con las lígulas divididas, entre ellas $A$. tristis. Por lo tanto, el material contenido en dicho pliego no puede seleccionarse como tipo de A. tristis L. (1753), pues el nombre anotado por Linneo en el pliego es muy posterior a la descripción de la especie.

El tipo, pues, ha de buscarse entre los otros elementos del protólogo linneano. La referencia a Royen (1740: 178), "Jacoboea africana, stoebes facie, flore amplo, petalis radiantibus trifidis. Volk. Norib. 224", es una mención a la obra de Volckamer (1700: 224-225), en la que hay una descripción bastante detallada de la planta, y en su "addenda \& subjungenda" aparece la lámina, sin numeración, de "Iacoboea Africana Stoebes facie, flore amplo, petalis radialib. trifidis". En dicha figura se representa una planta casi completa, con hojas bipinnatífidas, largamente pecioladas y un capítulo en floración con las lígulas trífidas (fig. 1). Curiosamente, esta referencia a Volckamer la recogió Linneo cuando describió Arctotis superba L. (1756). Otro elemento que menciona Linneo en el protólogo fue el de Breyne (1739: 27, tab. XV. fig. 1). El icono de la táb. XV fig. 1, en el que anota "Anemospermos afra folio \& facie taraxaci incanis", representa una planta en floración muy parecida a la de la obra de Volckamer, anteriormente comentada, pero con el pecíolo de las hojas mucho más corto y el limbo pinnatisecto, con los lóbulos enfrentados y el raquis dentado. De las dos figuras disponibles se elige la de "Iacoboea Africana Stoebes facie, flore amplo, petalis radialib. trifidis" publicada en la obra de Volckamer (1700), por ser la que representa más fielmente el capítulo de la planta de Linneo que se encuentra en su herbario principal y determinada por él como Arctotis calendulacea, a la que se aludió más arriba.

Tipificación de Arctotis superba L.

En el herbario de la Sociedad Linneana de Londres se conserva un pliego con el No. 1036.1, en cuya base figura con letra de Linneo "1 superba". "1" es el número dado por Linneo (1753: 992) a Arctotis tristis, y "superba" es el epíteto específico asignado por él (1756: 32) a su Arctotis superba en Centuria II Plantarum. Arctotis tristis está descrita como "flosculis radiantibus vicenis tripartitis" y Arctotis superba como "flosculis radiantibus quinquepartitis", pero para el segundo Linneo efectúa una descripción más amplia, sobre todo de las hojas y de las corolas más externas del capítulo: "Folia magis pinnata quam in reliquis; supra viridia, subtus albo tomentosa, pinnis dentatis bipartitis. Flosculi radiantes quinquepartitis: laciniis lateralibus brevioribus, profundioribus, lutei, subtus purpurei". Con posterioridad, Linneo (1763: 135-136) reconoció sus tres especies ya descritas dentro del género Arctotis : 1. A. superba, 2. A. tristis y 3. A calendula, y él mismo (1767: 991) reconoció, bajo Arctotis calendulacea, 5 variedades: $\alpha$ "A. flosc. radiant. sterlib. duodenis subintegris 3." [diagnosis idéntica a la de Arctotis calendula L. (1753)]; $\beta$ hypochondriacea "A. flosc. radiant. sterilib. trifidis media inflexa." [diagnosis semejante a la de Arctotis tristis L. (1753)]; $\gamma$ tristis "A. flosc. radiant. floribus quatripartitis 2." $[A$. tristis (1753) la describió como "tripartitis"]; $\delta$ coruscan "A. flosc. radiant. sterilib. tripartitis: exteriore trifida", y $\varepsilon$ superba "A. flosc. radiant. sterilib. quinquepartitis. 1." [la misma diagnosis que en Arctotis superba L.(1756)]. Consiguientemente, el número 1 que aparece en el pliego de Linneo, de Arctotis superba L., anteriormente comentado, puede hacer referencia tanto al de $A$. tristis como al de $A$. superba, al que también asignó este número, tanto en la segunda edición de su Species plantarum, como en la edición duodécima de su Systema Naturae, cuando la subordinó a $A$. calendulacea como variedad. Si este razonamiento fuera el correcto, el pliego del herbario principal de Linneo $\mathrm{N}^{\mathrm{o}}$ 1036.1 (LINN) podría elegirse como lectótipo de Arctotis 


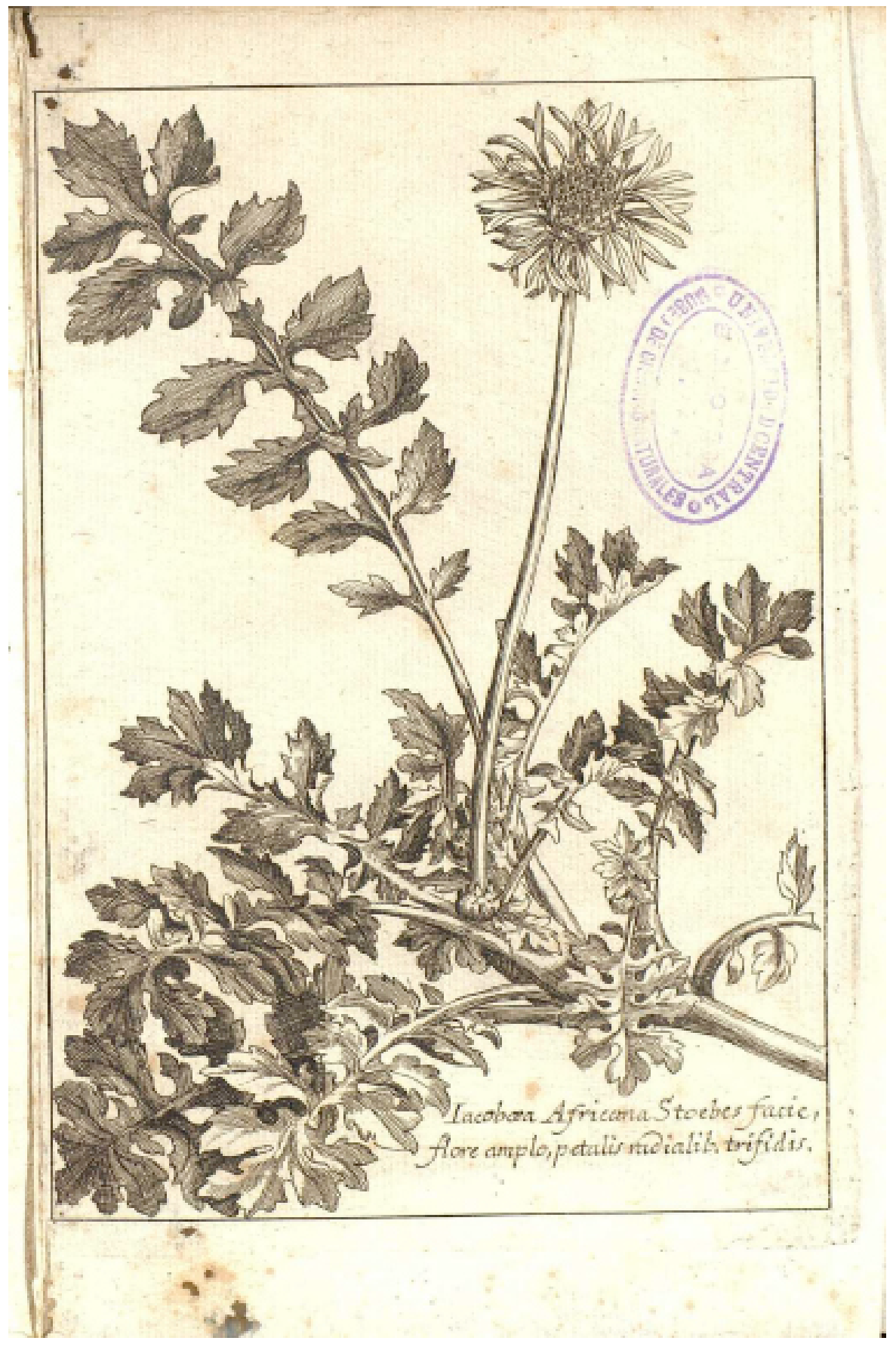

Figura 1.- Tipo de Arctotis tristis L. Lámina, sin numeración, de "Iacoboea Africana Stoebes facie, flore amplo, petalis radialib. trifidis" (Volckamer, 1700, en "addenda \& subjungenda"). 
superba L., pero en dicho pliego hay tres hojas individualizadas, un capítulo pedunculado entre ellas, y otro capítulo sin pedúnculo en la mitad superior del pliego. El capítulo con pedúnculo lo identificamos con Arctotis calendula L., y tanto las hojas como el capítulo carente de pedúnculo son plenamente coincidentes con la descripción original de Arctotis superba L., por lo que se han elegido como lectótipo las hojas y el capítulo sin pedúnculo del pliego del herbario de Linneo $\mathrm{N}^{\circ} 1036.1$ (LINN). Cuando Linneo describió Arctotis superba L., indicó como único elemento "Jacobaea africana, stoebes facie, flore ampliore, petalis radiantibus trifidis. Volk. norib. 224. t. 224 ?.”, lo que evidentemente, contradice claramente la descripción de Arctotis superba L. (véase más arriba).

\section{BIBLIOGRAFÍA}

BEAUVERD, G. -1915- Contribution à l'étude des Composées. Bull. Soc. Bot. Genève, Ser. 2, 17: 21-56.

BREYNE, J. -1739- Prodomi fasculi rariorum plantarum primus et secundus ... Icones rariorum plantarum. Danzig.

BROTERO, F. A. -1804- Flora lusitanica, vol. 1. Lisbon.

BROWN, R. -1813- Crystostemma. In: W. AITON, Hortus Kewensis 5: 741-742. London.

CANDOLLE, A. P. De-1838-Prodromus Systematics naturalis regni vegetabilis, vol. 6. Paris.

HARVEY, W. H. \& O. W. SONDER -1865- Flora capensis, vol. 3. Dublin, Cape Town.

HOFFMANNSEGG, J. C. G. Von \& H. F. LINK -1820-1834- Flore Portugaise, vol. 2. Berlin.

FUNK, V. A., A. E. HOLLAND \& R. CHAN -2007- Cymbonotus (Compositae: Arctotideae, Arctotidinae): an endemic Australian genus embedded in a Southern African clade. Bot. J. Linn. Soc. 153: 1-8.

GREUTER, W., M. AGHABABIAN \& G. WAGENITZ -2005- Vaillant on CompositaeSystematic concepts and nomenclatural impact. Taxon 54 (1): 149-174.

LESSING, C. F. -1832- Synopsis genera compositarum. Berolini.

LEWIN, K. -1922- Systematische Gliederung and geographische Verbreitung der Arctotideae Arctotidinae. Feddes Repert. Sp. Nov. 11: 1-82. LINNEO, C. -1753- Species Plantarum. Stockolm. LINNEO, C. -1756- Centuria II plantarum. Upsaliae. LINNEO, C. -1763- Species plantarum ed. 2, vol. 1. Stockolm.

LINNEO, C. -1767- Systema naturae ed. 12, vol. 2. Holmiae.

NORLINDH, T. -1977-Arctoteae- Systematic review. In: V. H. HEYWOOD, J. B. HARBORNE \& B. L. TURNER -eds.-, The Biology and Chemistry of the Compositae 2: 943-959. Academic Press: London, New York, San Francisco.

ROYEN, A. Van -1740-Florae Leydensis Prodromus. Lugduni Batavorum.

STEUDEL, E. G. -1821- Nomenclator botanicus, vol. 1. Stuttgart, Tübingen.

STEUDEL, E. G. -1840- Nomenclator botanicus ed. 2, vol. 1. Stuttgart, Tübingen.

VAILLANT, S. -1754- Neue Kennzeichen dreyer Classen von Pflanzen mit zusammengesetzeten Blumen, nämlich: der Cynarocephalarum, derer mit Artischockenhäuptern. Corymbiferarum, die zusammengesetzte, scheibenförmige Blumen tragen. Cichoracearum, weg-wartartiger. Königl. Akad. Wiss. Paris Phys. Abh 5: 545-613.

VOLCKAMER, J. G. -1700- Flora Noribergensis. Norinberg.

WENDLAND, I. C. -1798- Botanische Beobachtungen nebst einigen neuen Gattungen and Arten. Hannover.

WIJNANS, O. -1983- The Botany of the Commelins: a taxonomical, nomenclatural, and historical account of the plants depicted in the Monickx Atlas and in the four books by Jan and Caspar Commelin on the plats in the Hortus Medicus Amstelodamensis, 1682-1710. Wijnads: Rotterdam

Dirección de los autores. Departamento de Biología Vegetal y Ecología (Botánica). Facultad de Biología, apartado 1095.41080-Sevilla.mtalavera@us.es 